\title{
Queer Male Bodies and the Cinematic Liminal Beach
}

\author{
By Christopher Pullen
}

Keywords: queer cinema, the beach, Stranger by the Lake, Children of God, Soulbound, Undertow

Historically in film, the beach (or the seaside) for queer men, represents a place of sexual liaison, connoting liberty and danger, foregrounding the opportunity of cruising for sex (Worton 1998), and/or containment within heteronormative social space. This is evident where the partly clothed or nude body, displayed in places of leisure such as the beach, offers a site of vicarious sexual subjectivity. While certain beach settings offer queer men the possibility of identity affirmation and safety in forming a community, such as in Fire Island near New York (Newton 2014) or in Sitges near Barcelona (Clements 2006), the inherent 'risk' of 'cruising' for sex within the wider concept of the beach offers cinema producers a subcultural narrative trope that evokes otherness, sensation and danger.

The most prominent recent example of 'risk' may be Alain Guiraudie’s Stranger by the Lake (L'Inconnu du lac, 2013), where not only do sexual encounters occur, but also the close proximity to water and the presence of strangers frames a tension between leisure and danger. As Sean Redmond tells us:

\footnotetext{
the beach and its shoreline is designated as both a mortal and immortal location in cinema. [It can] bring death to those who visit it temporarily or go there to claim it as a permanent home, [and may be understood] as a liminal space, where regeneration possibilities are enacted. (Redmond 2013: 716)
} 
Queer bodies can feel welcomed yet displaced within beach settings, where families, children and heterocentric social worlds usually dominate, often leading to the expulsion, or the punishment, of the queer body. Cinema is aware of this narrative archetype in setting the queer male body within the liminal beach, productively employing this device within a wide range of texts that has more recently included affirmative, and deeply sensitive pleasure. This is notably apparent in the Academy Award winning film Moonlight (2016), where a youthful queer male couple experience their first sexual encounter sat on the beach at night, and later in the film many years later, we hear the rippling of the sea, lapping and receding and as they are reunited, to became romantically entwined at the close of the film. The queer male within the beach setting offers a representational nexus of pleasure, vulnerability and possible fulfilment.

In this article, I examine the cinematic context of the beach setting for queer men, not only exploring a historical and theoretical body of work that includes Stranger by the Lake (among many others), but also by foregrounding three transnational films for their deeper connection to emotion and affect: Children of God (2010), set in the Bahamas, directed and scripted by Kareem Mortimer; Soulbound (Teus olhos meus, 2011), set in Brazil, directed and scripted by Caio Sóh; and Undertow (Contracorriente, 2009), set in Peru, directed and scripted by Javier Fuentes-León. I explore the wider western-centric context of the affective queer male body and its relationship to the seaside, framing a historical cinematic landscape that highlights the significance of French cinema. ${ }^{1} \mathrm{I}$ argue later that the queer male body is represented as vulnerable within these transnational cinematic forms and the 'queer diaspora’ (Patton and Sánchez Eppler 2000), framing the affective potential of 'feeling', rather than politicizing 'being'. Hence while these texts clearly frame the 
notion of the queer male in terms of identity, they pay less attention to political goals, or wider notions of subjugation; rather, they focus on the affective potential of the self, based on senses, memories and feeling.

\section{Affect and the transnational}

Sara Ahmed has argued that 'to make [an] impression is dependent on past histories, which surface as impressions on the skin' (2007: 2). For the queer male cinematic body this might involve a focus on feeling and tactility, representing the body as living within, and facing up to, dominant history. The representation of the sensory nature of queer skin potentially challenges histories of subjugation within culture and society, which for queer bodies often involved punishment, absence, rejection and/or denial. Hollywood films historically have ignored the existence of queer men, or reduced them to stereotypes and/or assigned them as murder victims, or killers themselves (Russo 1987). Although more recent films such as Brokeback Mountain (2005), A Single Man (2009) and Moonlight (2016) seem progressive for their ability

to reach wider audiences with enduring narratives of commitment, often they

deliberate on tragedy, mortality, containment or personal loss as a central focus of attention. . While my case studies largely do involve issues of mortality, I argue that

they focus less on expelling the queer body before the closure of the narrative as if it were incongruous within the normative world (as might occur in Hollywood); rather, they focus on the vulnerability of the body, offering a sustained focus on such vulnerability. Such actions, I argue, provide a deeper layer of meaning, in defining the queer body as sentient, rather than abject.

As Ahmed tells us, ‘[i]n shaping one’s approach to others, compulsory heterosexuality also shapes one's own body, as a congealed history of past 
approaches' (2004: 145). The queer body is shaped by histories of denial, abjection and dominant moral coding, framing notions of absence or punishment. Despite this, the queer body could challenge those histories through acting as an agent for change or reinvention. I argue that my case studies Children of God, Soulbound and Undertow, as part of transnational cinema, offer this potential for the representation of queer men through their blurring of identity forms, challenging not only the dominance of the nation-state, but also the concept of the ideal citizen as not necessarily fixed in social/sexual identity.

While my main case studies are set in South America or the Caribbean and are directed by filmmakers coming from these areas, seeming like exemplars of national cinema, ${ }^{2}$ I argue that these films rely less on issues of national identity and rather develop a sense of imagined community (Higson 2006) that questions the notion of ideal citizenship. These texts evoke the transnational, through framing 'the borderline engagements of cultural difference [which] may confound our definitions of tradition and modernity' (Bhabha 2004: 3). They offer the potential of transnational queer cinema to address, or represent, diverse social and sexual communities. As Rosalind Galt has suggested, with particular regard to Argentinian cinema: 'queerness [is] a significant mode of world cinema' (2013: 62); a 'queer’ transnational film might speak to an international queer or mainstream community, as much as represent a local nation-state (see Grossman 2000 and Ka-Hang 2012).

\section{Queer diaspora and the liminal beach}

Notions of nationhood are challenged within transnational cinema, where aspects of queer postcolonialism and the potential of the queer diaspora may be framed (see Hawley 2001; Patton and Sánchez Eppler 2000). Hence while the hierarchy of the
Comment [CP9]: yes Comment [E10]: the liminal beach? Comment [CP11]: Took out at the same time 
western-centric focus of Hollywood and European cinema offers a foundation for queer spectatorship, directing the way we might view narratives and characters (see Farmer 2000; Griffiths 2008), we must also consider the wider global context of queer audiences that are from diverse non-white, non-western and developing-world communities and cultures, seeming like a queer diaspora. This might be evident where the main case studies in this article represent the queer diasporic body as not necessarily fixed to any national or dominant cultural identity (such as white queer identity [see Logie and Rwigema 2014]), framing the beach or seaside environment as a liminal space, not fixed to terrain, or social order.

I argue that the representation of queer 'diasporic' men within the transnational beach setting offers new scope for identity relative to location. As Fiona Handyside tells us, '[t]he beach and the cinema [...] share a range of characteristics as explorations of the border between life and death, stillness and movement, which has generally been neglected within studies of cinematic spatiality, in favor of the cityscape’ (Handyside 2013: 672). Historically, particularly for queer male identity, the notion of the city and the significance of urban space has framed the potential for identity and community building (D’Emilio 1983, 1990). Within filmic discourse this is evocatively discussed in the queer road trip film The Adventures of Priscilla Queen of the Desert (1994), where in the words of the fictional character Bernadette (played by Terence Stamp) we are told:

It's funny. We all sit around mindlessly slagging off that vile stink-hole of a city. But in its own strange way, it takes care of us. I don't know if that ugly wall of suburbia's been put there to stop them getting in, or us getting out. 
The notions of community building and also safety within the metropolis, offer resonance for queer identity, and as The Adventures of Priscilla Queen of the Desert reveals, once outside the city, and within nature, potentially queer men are vulnerable.

However, as my case studies reveal, there is new scope for the queer body, through moving outside the confines of the urban setting. The liminal setting of the beach and the sea, offers resonance for transnational queer diasporic bodies, as they are no longer fixed within any particular place. Consequently, queer diasporic bodies do not need to adhere to distinct national or cultural heritages; rather, a sense of fluidity and mobility pervades. For example, in Undertow when a queer man (Miguel) takes part in a local funeral ritual (discussed further below), the imagined disconnection between queer men and local traditions is blurred, offering a sense of hybridity and new form.

The cinematic representation of the diasporic queer male as a new form within the beach setting, as defined in my case studies of Children of God, Soulbound and Undertow, offers a complex site of imagination based on intimate senses and intuitions, rather than on exhibiting overt political ideals. The foundation of this may be traced back through a diverse range of western-centric forms, which, while they do not explicitly foreground the queer diaspora, or necessarily the transnational, frame the context of affect and liminality.

\section{The western-centric queer body and the cinematic beach}

An early covert representation of the western-centric queer male within the beach setting occurs in Suddenly Last Summer (1959), where through flashback sequences we discover details of the demise of Sebastian Venable, who is murdered by

Comment [E12]: a new form?
$\begin{aligned} & \text { Comment [CP13]: Added as a new } \\ & \text { form }\end{aligned}$


cannibalistic youth while on holiday abroad. Sebastian had taken a holiday with his cousin Catherine (played by Elizabeth Taylor), who recalls to a psychiatrist that she had been used as 'bait' for him to attract male sexual partners (see Figure 2). ${ }^{3}$ Sebastian seems distant and 'absent' in the film as his identity is aesthetically obscured or concealed, through the camera avoiding close-ups of his face, resisting any sustained visual composition of his identity. Sebastian's mother Violet (played by Katherine Hepburn) frames the vulnerability of her son through recalling the memory of a previous holiday in the company of Sebastian, while overlooking a beach:

\footnotetext{
VIOLET: I saw the sand; all alive, and all dark, as the new-hatched sea turtles made their dash for the sea, while the birds hovered and swooped to attack, and hovered and swooped to attack. They were diving down on the sea turtles, turning them over to expose their undersides, tearing their undersides open, and rending, and eating their flesh. Sebastian guessed that possibly only 100th of one per cent would escape to the sea [...] Nature is cruel. Sebastian knew it all along. He was born knowing it. Not I, I said no; no - those are only turtles and birds, not us. I didn’t know that it was us - that we are trapped in this devouring creation.
}

Relating predators, their prey and the limits of the natural and primordial, the representation of Sebastian in Suddenly Last Summer, foregrounds the spectre-like presence of the queer male, seeming to possess no body, but able to comprehend the brutal nature of the dominant order.

Later, The Detective (1968) similarly frames the queer male as outside, other and abject. Set on the waterfront of New York, The Detective focuses on the murder of a young gay man, by a potential lover who cannot accept his queer desire. In a 
pivotal sequence we see a range of sexual outcasts, in the proximity of the port, represented as deviants who cannot resist their mutual affection. Early representations of the queer male within the proximity of the beach (or the waterfront), such as Suddenly Last Summer and The Detective, frame queer male identity as troubled and unfulfilling, disavowing any meaningful sense of feeling, relying more on punishment, rather than offering empathy or a developed emotional universe.

The queer male became more explicitly represented within the beach setting in Death in Venice (Morte a Venezia, 1971). The film offers a deeper sense of feeling, framing the gaze and desire of a middle-aged man for a beautiful male youth, who is observed while on holiday with his parents and siblings. The close of the film where Gustav dies on the beach, in some senses paying for his impossible desire, frames the queer body as human, yet vulnerable, foregrounding mortality and the oppressive nature not only of the social order, but also of the seaside climate, as heat reflected on the sand. This all-consuming heat, connoting the oppressive heterosexual order, not only makes Gustav's pale make-up run, but it also hastens his demise from cholera.

However, while mainstream cinema had constructed the queer body as existing within the domain of the beach or the sea, the queer body was rarely immersed in the water, or represented as a dominant social force by the sea. Despite this, New Queer Cinema (Ritch 2013) often foregrounded the immersive body, specifically in films responding to the AIDS crisis. Films such as Love! Valour! Compassion! (1997), Parting Glances (1986) and The Living End (1992), all present the queer body as within the water, or in close proximity to the water in dominant queer social groupings.

However, French queer cinema has explored the queer body in relationship to the seaside, within more mainstream settings. For example, Andre Téchiné’s 
groundbreaking film Wild Reeds (Les Roseaux sauvages, 1994) frames queer male youth within river water, foregrounding the immersion of their bodies in relation to liberation, and self-awareness. In this sense, the representation of water as clinging to and supporting the queer body, references the haptic and sensual affective property of film, which Laura U. Marks (2000) relates to intercultural cinema, as it 'draws from many cultural traditions, [evoking] memories both individual and cultural, through an appeal to nonvisual knowledge, embodied knowledge, and experiences of the senses, such as, touch smell and taste' (Marks 2000: 2). In this sense, the representation of the queer body as feeling, remembering and living through the experiential moment, located within the natural seaside, involving setting, location and articulation, foregrounds the queer skin as sensual, and coherently responsive. As Fiona Handyside (2012) tells us in considering the films of François Ozon, '[i]n their timelessness, beaches become queer sites, undoing heteronormativity's insistence on a linear march towards the future and queering affective relations by insisting on the coexistence of differing experiences of time’ (Handyside 2012: 56).

Such temporal configuration is particularly evident in films where death occurs near to, or on, the beach. Téchiné’s I Don’t Kiss (J'embrasse pas, 1991) and Ozon’s Time to Leave (Le Temp qui reste, 2005) both feature queer males who ultimately arrive at a beach to die. While in the former the lead protagonist is dying of AIDS, and in the latter he is dying of cancer, it is the relationship of the beach to childhood memories, and the passing of time, which suspends a need for linear timeframes. Hence childhood and death coexist, as a temporal representation. As Handyside advises, referencing Elizabeth Grosz (1995), 'time and space are never experienced as mathematical or geometrical abstractions but [are constructed] in and through our bodies’ (Handyside 2012: 55). 
This similarly occurs in Sebastien Lifshit’s Come Undone (Presque rien, 2000); however, rather than death as a culmination of an illness, the central protagonist returns to a family holiday home by the seaside in order to recuperate after a suicide attempt, and the beach becomes a liminal space for healing and transition. In contrast, Olivier Ducastel's and Jacques Martineau's Cote D’Azur (Crustacés et coquillages, 2005), presents a warm-hearted comedy of errors, representing a mistakenly identified queer son and the desires of a 'real' queer son, within an everyday family household in a beach holiday setting. At the close of the film a comedic musical number is presented, where the cast perform with their ideal sexual and romantic partners. However, more recently, Alain Guiraudie’s Stranger by the Lake foregrounds water as a lucid presence that envelops the morality of a queer male in search of partnership, within the thriller and horror genre. Although witnessing the murder of another queer male, the central protagonist suspends issues of culpability, in favour of sexual satisfaction with the murderer. While offering a 'negative' stance on the morality of queer men who are drawn to the lakeside where they may find sexual encounters, this film nevertheless frames the active queer body as mobile, rather than purely culpable in moral terms, or corporeally ephemeral.

However, the western-centric 'foundational' case studies above mostly involve the representation of North American or European queer male identities. The main case studies below - Children of God, Soulbound and Undertow - however, as exemplars of transnational cinema, offer a more developed focus on 'other identities', such as non-white and non-western. I argue that these films more intuitively frame the potential of affect though their focus on the queer diaspora (discussed above), breaking down barriers of national and cultural identity. 


\section{Transnational queer diaspora: Children of God, Soulbound and Undertow}

Children of God, Soulbound and Undertow focus on the queer diasporic body as situated within the context of nature, relating sensitivity and memory. The queer body is represented as part of the everyday cultural and ecological world, rather than in opposition, or in contrast to it. The transnational narratives of Children of God, Soulbound and Undertow, place a particular focus on the problem, and promise, of the artist's idealized dream world. This is evident in the struggle of the photographer/painter/musician attempting to capture a particular moment in time through the production of art, relative to their inherent narratives of personal becoming, and the desire for a partner, which crosses social and cultural divides.

In Children of God, a young gay male Latino artist called Johnny, struggles for acceptance within his community. On a holiday vacation to improve his painting techniques he meets Romeo who is black, and a covert bisexual local character, whom he used to know at school. However, this romance is not fulfilled, as later a former covert lover of Johnny's murders him during a public altercation. In Soulbound, the story concerns Octavio, a middle-aged music producer who meets a youth called Gil, an unemployed musician with a rootless life, who drinks excessively. Octavio and Gil are drawn together after meeting late one night at a beach bar, both looking for solace. However, romance is not possible, as Gil is later revealed to be the son of Octavio, engendering their relationship as incestuous. In Undertow, Santiago is a photographer and a painter, who had left the village of this birth to gain education in arts-based skills. He returns to the village to meet up with his covert lover Miguel, who had remained in the village taking on the traditional role of a fisherman, and is now married and about to become a father. Through an accident after a confrontation between the two lovers, Santiago drowns when his body is trapped on the sea floor. 
Santiago then appears as a ghost visible only to Miguel, and later is buried at sea, as part of a local funereal ritual tradition.

All three texts focus on the cultural and social divides between the main romantically coupled characters, highlighting the vulnerability of their queer bodies, relative to the notion of time passing, counterpointing imaginations, dreams and memories. As Elizabeth Grosz advises:

\begin{abstract}
time is perhaps the most enigmatic, the most paradoxical, elusive and 'unreal' of any form of material existence [...] time is neither fully 'present', a thing in itself nor is it a pure abstraction, a metaphysical assumption that can be ignored in everyday practice.
\end{abstract}

(Grosz 2004: 4-5)

In this way, the narrative construction and aesthetic signifiers within Children of God, Soulbound and Undertow, suggest that time is suspended and malleable, rather than fixed. As Mary Anne Doane tells us, referencing the work of Walter Benjamin (1969) Comment [CP20]: Changed as suggested

with regards the use of montage in relating narrative and time, this functions 'not so much to confer meaning, but to rapidly accumulate and juxtapose contingencies’ (Doane 2002: 15). Within my case studies, the queer body is a key narrative source, framing the introspective and the reflective.

This is primarily evident in a key sequence from Children of God, where in a cave by the sea Johnny recalls to Romeo his thoughts on death.

\footnotetext{
When you die, your heart stops, but your brain keeps working for five minutes, and in those five minutes you dream, for five minutes. But there is no sense of time in the dream world, so that the dream lasts forever and ever.
} 
Foreshadowing the close of the film when Johnny dies and the dream world is made real, this sequence occurs just after Romeo teaches Johnny to float in water (see Figure 3). Johnny has a fear of people touching him, and there is an unwillingness to let go. Romeo instructs Johnny: 'Now think of the most special place you have ever loved. It can be real or from the imagination. You feel safe, you feel beautiful, and you feel that you belong there.'

In these sequences, the discourses of Johnny and Romeo are related to the supportive, immersive and transparent sense of the water, suggesting that the psychological state of dreaming is central to your identity formation. In this sense, time is suspended, and feeling is made eternal. This offers a 'sensorial space' rather than a time- and history-based space, which Adriano D’Aloia relates to 'the transparency of the water and the act of vision, evoking a conception of film viewing as an immersive experience' (2012: 88). The nature of water, as it supports and envelops you, in the process of floating, swimming or diving, just off the land and not far from the cave, vivifies the nature of being fixed to geology and terrain. Yet as you are supported by the sea, within a fluid medium, it appears as if you live beyond the terrain, outside historical or measured time, able to resist notions of subjugation and abjection.

This is also apparent in Soulbound, where the representation of time seems compressed. Despite the discovery at the close of the film that lovers Octavio and Gil are father and son, suggesting a moral coding of time that is punitive, the theme of the duality of time is evident in the use of home movie footage within the film, foregrounding Octavio’s original female romantic partner Lígia, who is later revealed to be Gil's mother. These sequences are frequently intercut within the film, offering a 
sense of repetition and build up, in the manner that one might review old home movie footage not only to reminisce, but also to review and reconstruct the past.

Lígia is constructed as an ideal partner, evident not only in the manner that Octavio discusses her, but also apparent in the construction of the home movie content. The sequences of Lígia on the beach, running in and out of the water, set many years in the past, are juxtaposed with the narrative of Octavio and Gil on the beach, on the night of their first encounter. The suggestion is that Octavio has found new love in his pursuit of Gil. However, this repetition of the home movie footage, suggesting a suspension of time, and a dream-like reimagining, is counterpointed with a nightmare, evident in the theme of incest. This is foreshadowed not long after Octavio and Gil first meet, as they lie on the beach and converse with a sense of already knowing each other (see Figure 4):

GIL: At last someone that doesn’t make me feel fucking lonely. [...]

OCTAVIO: Gil, the others come and go in our lives, just like the waves come and go into the sea. They come and they fade away. Just like people in our lives disappear. But the sea is right there. And the deeper you go the quieter and the lonelier it is. One has to be immense like the sea to know how to be lonely.

GIL: Wow. Octavio, thank you [...] for everything man. [...]

OCTAVIO: Funny, I see myself in your eyes, you know?

The sense of their mutual lisolation, seeming outside the domain of real time, and existing in a dream-like reimagining of time, as represented in the presence of home Comment [E23]: mutual isolation? Comment [CP24]: Changed as movie footage of Lígia, suggests that their relationship is close, and potentially eternal. However, unlike the footage of Lígia, which is presented in a free-flowing and carefree manner, evident in the playful movement of both the characters and the 
camera itself, the framing of Octavio and Gil references the impossibility of their relationship. This is evident in a key sequence of a shot with both men lying on the beach, with close-ups looking down on their faces from above, making them seem upside down. While this is intercut with images of the beach, and the movement of the camera as Octavio partly sits up, there is a sense of disconnection. Hence, while this sequence focuses on their 'imagined' connection, revealing that Octavio has found a new love that equals his connection with Lígia, the concept of isolation and impossibility is also framed, which connotes tragedy.

This is particularly evident in Undertow, in the representation of the death of Santiago, which occurs after Miguel and Santiago’s argument. In an unstable mental state, Santiago goes swimming and becomes trapped on the seabed, seemingly caught there by natural forces and the geological order. When Miguel discovers Santiago's body a little later, rather than release it, he secures it to the seabed. We sense that he does this in order to conceal Santiago’s death, potentially because he does not want his queer relationship to be discovered by the local community, and in another sense he secures the body to not let him go. Thus duality here represents the tragedy of a life cut short, and also the need for the body to remain, to not pass on. This is Comment [CP27]: Changed as particularly evident in the use of sound and movement in juxtaposition to the visual representations.

Notably, the sound of the sea is persistent in Undertow to connote the close proximity of the village to the sea. This is evident in the recurring sound of the sea Comment [CP28]: Changed as suggested rhythmically crashing upon the beach, and the drawing back of pebbles as the sea routinely recedes. The aural movement of the sea sounding back and forth connotes Comment [CP29]: Changed as suggested the idea of psychological reflexivity and the sense of time as suspended, as the sea moves forward and backward within the motion of waves and tides. Thus, making a 
connection and disconnection with the physical beach, the surface as moving and being touched by the water, references the thought processes of thinking through, and the relationship between measured and metered time in contrast with experiential and dream-like time. The sound of the sea in this manner permeates the diegetic narrative of the film, only to be interrupted by the sequences where Miguel is searching underwater for Santiago's body. In these sequences, the diegetic sound changes to the Comment [CP30]: Changed as suggested. sombre and muted sound of 'underwater', evident in sounds of swimming through water and the recurrence of bubbles, which are expelled in breathing out underwater. However, in terms of narrative construction this underwater search for Santiago's body is fragmented and intersects a number of scenes where Miguel meets with the ghost of Santiago on varying occasions. In this sense, the rhythmic alteration between the sound of the sea as heard in the village, and the sound of the sea as heard by Miguel, in search of Santiago, breaks with the normative diegetic world, foregrounding the notion of immersion, affect and suspended time.

This relationship between land and sea is further developed when Miguel eventually returns Santiago's body to the sea, as part of a local ritual reserved for fishermen. We see Miguel act as a pallbearer (Figure 5), now standing out in the community after publicly announcing his love for Santiago. With a minority of village supporters, Miguel carries Santiago's body to the boat. Then, alone on the boat, he Comment [E31]: confirm change Comment [CP32]: yes fine commits Santiago's body to the sea, while Santiago briefly returns as a ghost, to embrace and kiss Miguel. In this sense, the being above water, and the resting below, as becoming part of the natural ecological order, represents a shift between the oppressive cultural world, and the natural or dream-like order. While Santiago was consumed by the sea in an earlier scene, this representation foregrounds a haptic presence, where touch, memory and feeling are brought together in the sense of 
movement between land, sea and body. This presents an ecological rhythm, between the queer body and the landscape, encouraging as sense of endlessness and connectivity, framing the notion of time, | suspension and affect.

Children of God, Soulbound and Undertow define the queer diasporic body as Comment [E34]: confirm insert of comma vulnerable and subject to affect. In Children of God, while Johnny ultimately is murdered in a hate crime, the victim of a former lover, our focus is not on the moral universe, but rather on senses of feeling and loss. In Soulbound, while we are presented with a tragic narrative of abject forbidden love, we consider the loneliness and isolation of the characters with the knowledge that this can never be resolved. In Undertow, while Santiago dies in a tragic accident and we consider that Miguel is partially culpable, it is the coming to terms with death that ultimately resonates. All these texts demonstrate the vulnerability of the queer body, not necessarily providing answers, but rather expressing ways of feeling.

\section{Conclusion}

As Suddenly Last Summer reveals in the cypher of the vulnerable sea turtles that do not make it to the sea but are devoured, the persecutions felt by queer bodies are legion, and abjection is more likely than acceptance. This leads us to consider that the dream world in Children of God might actually be a permanent state of death; the ritual return of the queer body to the sea in Undertow may be a hollow cultural concession; and the controversial incest narrative within Soulbound does not challenge stereotypes of queer sexuality, but actually frames aspects of shame and guilt. Despite this, I argue that the representation of the queer body within all these films iterates a sense of feeling and connectivity, through their connection with water - a fluid medium that has no fixed constitution (unless frozen) - and the liminal 
landscape - a fixed terrain that is not fixed at all, but is between places. Such representations challenge the colonial order, stimulating a focus on the queer diaspora, as individuals not fixed to specific locations and communities, but existing within liminal contexts that frame the potential of the sensual affective queer body.

Hence, in Children of God, Soulbound and Undertow there is a foregrounding of feeling and emotion, framing the natural or emotive order rather than the overpowering heterocentric social world. There is a resistance to the notion of a fixed terrain, establishing a different way of viewing the queer body as not fixed to a place or an identity, but rather, as grounded in a sensory, emotive and affective state. The cinematic queer body represented within the transnational beach setting, places a focus not on being and resisting, but more on working through, on challenging the heterocentric order. These contemporary representations of the affective queer body are based on the potential to feel, reflect and sense that you are among other bodies, sharing a sense of community through feeling. While avoiding assignations of 'lesser than', or 'never could be', the cinematic queer body senses the surface, while reflecting the depths.

\section{Contributor's details}

Christopher Pullen is a Principal Academic in Media Theory, at The Faculty of Media and Communication, Bournemouth University, UK.

\section{References}

Ahmed, S. (2004), The Cultural Politics of Emotion, Edinburgh: Edinburgh University Press. 
(2007), Queer Phenomenology: Orientations, Subjects, Others, Durham:

Duke University Press.

Barnard T. and Rist, P. (eds) (1999), South American Cinema: A Critical

Filmography, 1915-1994, Austin: University of Texas Press.

Benjamin, W. (1969), 'On Some Motifs in Baudelaire’, in H. Arendt (ed.),

Illuminations, New York: Schocken, pp. 155-200.

Comment [E39]: page numbers?

Comment [CP40]: added

Bhabha, H. (2004), The Location of Culture, London: Routledge.

Bosworth, P. (1978), Montgomery Clift: A Biography, New York: Harcourt.

Cham, M. B. (1995), Ex-Iles: Essays on Caribbean Cinema, Trenton: Africa World Press.

Clements, P. (2006), Out and Around Barcelona and Sitges, London: Thomas Cook Publishing.

D’Aloia, A. (2012), 'Film in Depth: Water and Immersivity in the Contemporary Film Experience', Acta Unv: Sapientiae, Film and Media Studies, 5, pp. 87-106.

D’Emilio, J. (1983), Sexual Politics, Sexual Communities: The Making of a Homosexual Minority in the United States 1940-1970, Chicago: University of Chicago Press. (1990), 'Gay Politics and Community in San Francisco Since World War II', in M. Duberman, M. Vicinus and G. Chauncey (eds), Hidden from History: Reclaiming the Gay and Lesbian Past, New York: Meridian, pp. 456-73.

Doane, M. A. (2002), The Emergence of Cinematic Time: Modernity, Contingency, the Archive, New York: Harvard University Press.

Farmer, B. (2000), Spectacular Passions: Cinema, Fantasy, Gay Male Spectatorships, Durham: Duke University Press.

Comment [E42]: issue number? Comment [CP43]: This is unclear, I think this may be a volume number, there is no issue number 
Galt, R. (2013), 'Default Cinema: Queering Economic Crisis in Argentina and Beyond', Screen, 54:1, pp. 62-81.

Golz, D. B. (2010), Queer Temporalities in Gay Male Representation, New York: Routledge.

Griffiths, R. (ed.) (2008), Queer Cinema in Europe, Bristol: Intellect.

Grossman, A. (ed.) (2000), Queer Asian Cinema: Shadows in the Shade, New York: Haworth.

Grosz, E. (1995), Space, Time and Perversion, London: Routledge. (2004), The Nick of Time, Durham: Duke University Press.

Hammond, B. and Redmond, S. (2013), 'This Is the Sea: Cinema at the Shoreline', Continuum: Journal of Media and Cultural Studies, 27:5, pp. 601-02.

Handyside, F. (2012), ‘The Possibilities of a Beach: Queerness and François Ozon’s Beaches', Screen, 53:1, pp. 54-71.

(2013), ‘Ghosts on the Sand: François Ozon’s Haunted Beaches’, Continuum: Journal of Media and Cultural Studies, 27:5, pp. 663-75.

Hawley, J. C. (ed.) (2001), Post-Colonial Queer: Theoretical Intersections, New York: State University of New York Press.

Higson, A. (2006), 'The Limiting Imagination of National Cinema', in T. Ezra and T. Rowden (eds), Transnational Cinema: The Film Reader, London: Routledge, pp. 15-25.

Johnson, R. (1995), Brazilian Cinema, New York: Columbia University Press.

Ka-Hang, J. H. (2012), ‘A Chinese Queer Discourse: Cam and Alternative Desires in the Films of Yon Fan and Lou Ye', in C. Pullen (ed.), LGBT Transnational Identity and the Media, Basingstoke: Palgrave MacMillan, pp. 290-307. 
Logie, C. H. and Rwigema, M. J. (2014), “"The Normative Idea of Queer Is a White Person”: Understanding Perceptions of White Privilege Among Lesbian, Bisexual, and Queer Women of Color in Toronto, Canada', Journal of Lesbian Studies, 18:2, pp. 174-91.

Marks, L. U. (2000), The Skin of the Film: Intercultural Cinema, Embodiment, and the Senses, Durham: Duke University Press.

Martin, M. T. (1997), New Latin American Cinema: Theory, Practices, and Transcontinental Articulations, Volume One, New York: Wayne State University Press.

Newton, E. (2014), Cherry Grove, Fire Island: Sixty Years in America's First Gay and Lesbian Town, Durham: Duke University Press.

Patton, C. and Sánchez Eppler, B. (eds) (2000), Queer Diasporas, Durham: Duke University Press.

Redmond, S. (2013), 'Death and Life at the Cinematic Beach', Continuum: Journal of Media and Cultural Studies, 27:5, pp. 715-28.

Russo, V. (1987), The Celluloid Closet, rev. ed., New York: Harper \& Row.

Ritch, R. B. (2013), New Queer Cinema: The Director's Cut, Durham: Duke University Press.

Shaw. L. and Dennison, S. (2007), Brazilian National Cinemas, New York: Routledge.

Worton, M. (1998), ‘Cruising (Through) Encounters', in O. Heathcote, A. Hughes and J. S. Williams (eds), Gay Signatures: Gay and Lesbian Theory, Fiction and Film in France, 1945-1995, Oxford: Berg, pp. 29-49.

\section{Suggested pull quotes}


Early representations of the queer male within the proximity of the beach (or the waterfront), such as Suddenly Last Summer and The Detective, frame queer male identity as troubled and unfulfilling...

French queer cinema has explored the queer body in relationship to the seaside, within more mainstream settings.

The transnational narratives of Children of God, Soulbound and Undertow, place a particular focus on the problem, and promise, of the artist's idealized dream world.

in Children of God, Soulbound and Undertow there is a foregrounding of feeling and emotion, framing the natural or emotive order rather than the overpowering heterocentric social world.

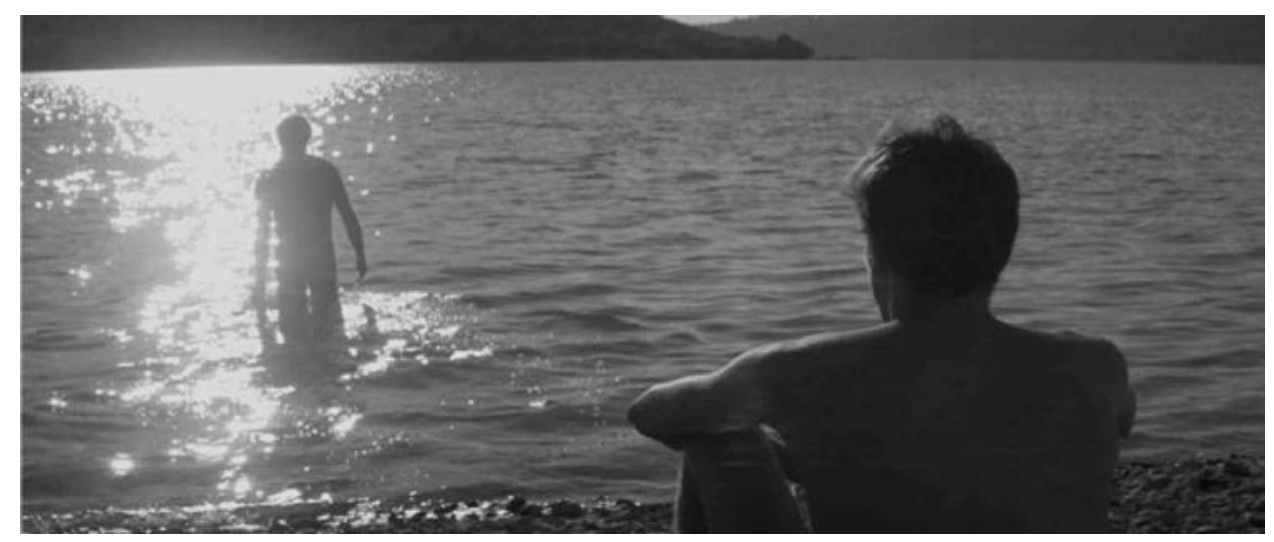

Figure 1: A scene from Stranger by the Lake (L'Inconnu du lac, 2013), evoking the danger of sexual desire. 


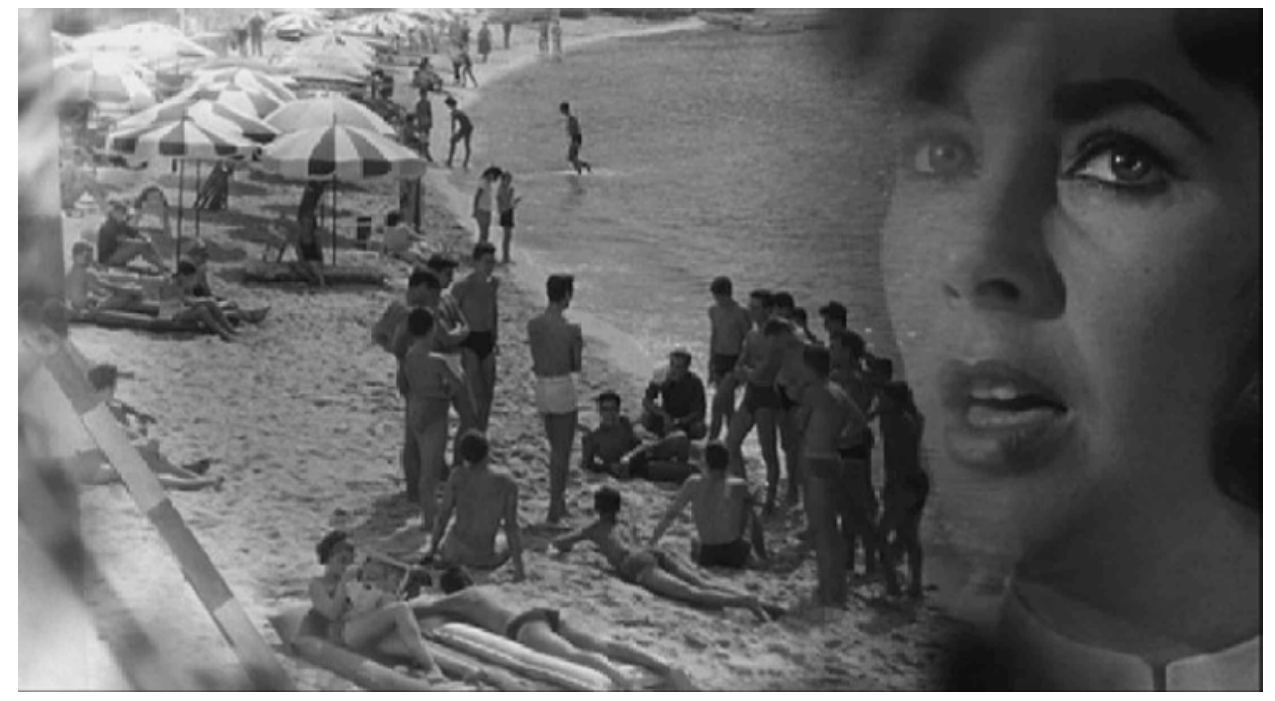

Figure 2: Catherine recalls her relationship with Sebastian in Suddenly Last Summer (1959).

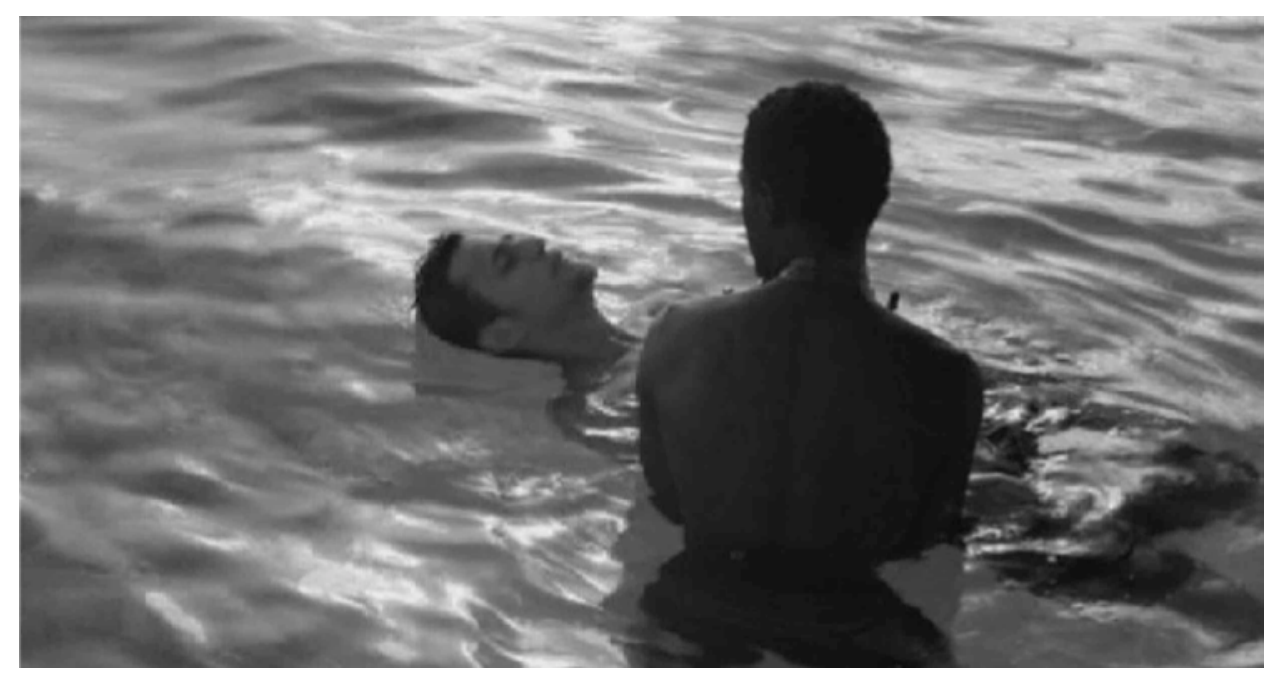

Figure 3: Johnny is supported by Romeo in Children of God (2010). 


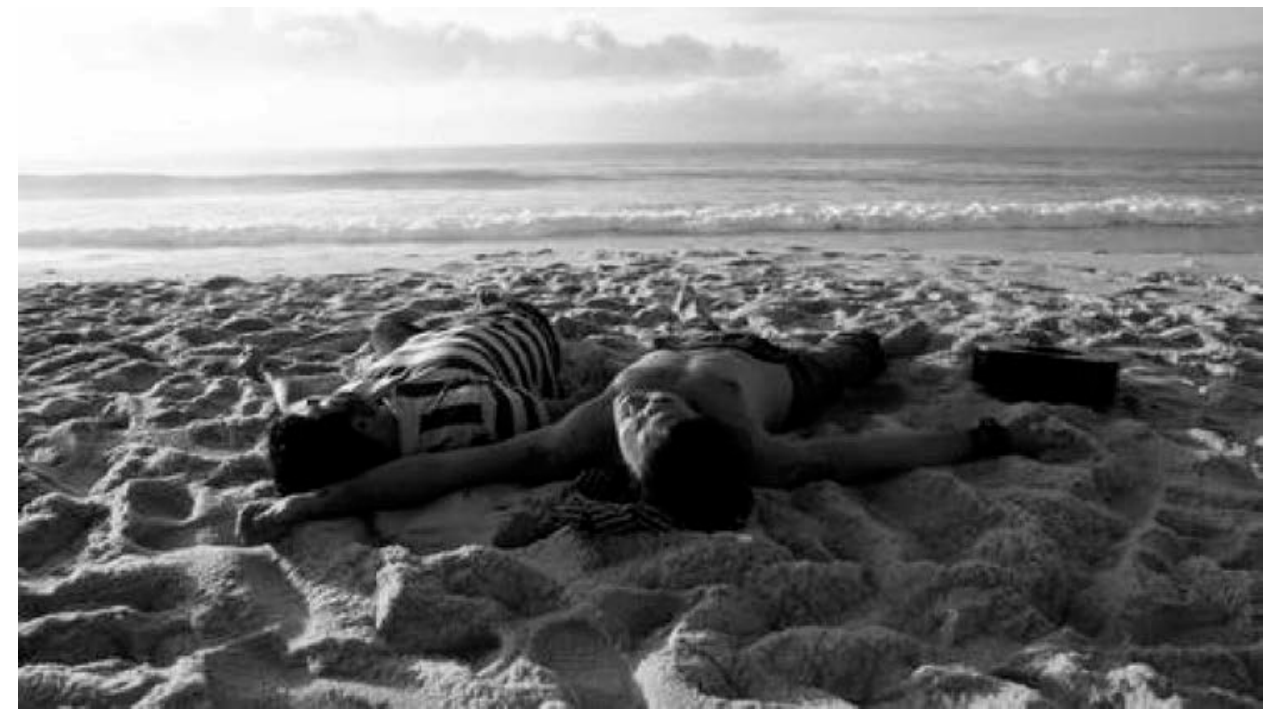

Figure 4: A scene from Soulbound (Teus olhos meus, 2011), signifying the impossibility of their relationship.

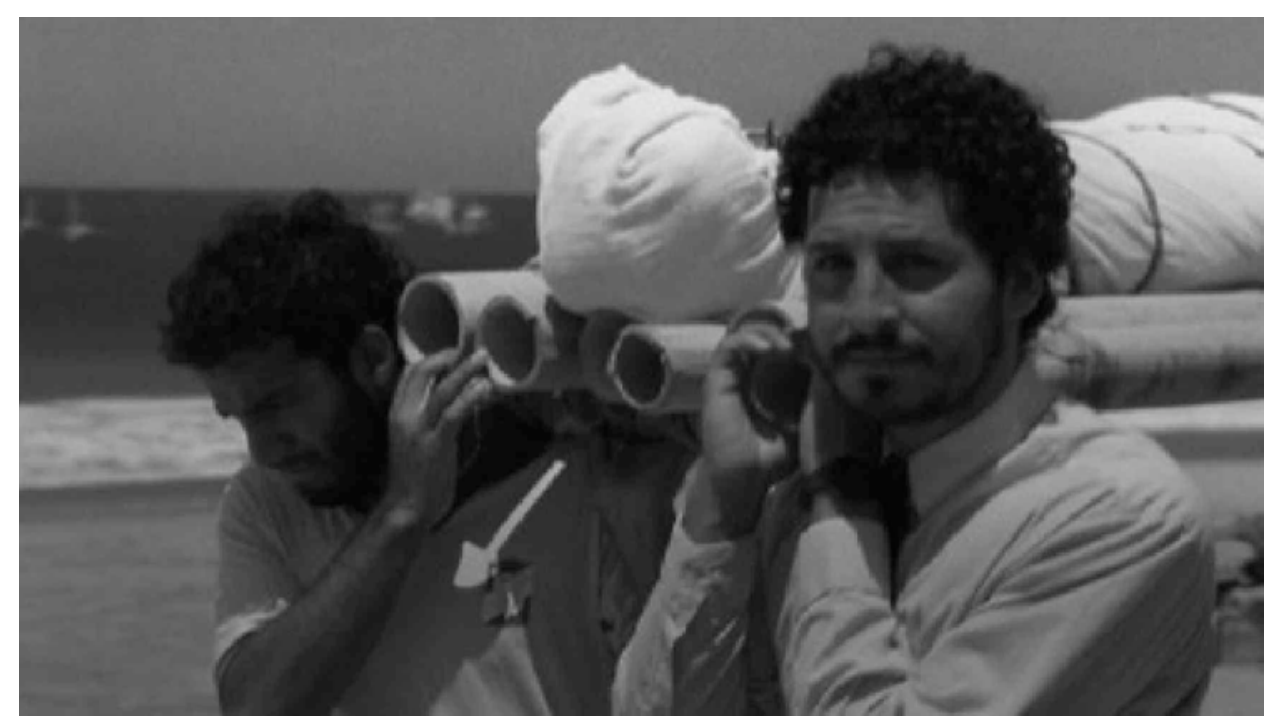

Figure 5: Miguel acts as a pallbearer for the burial of Santiago in Undertow

(Contracorriente, 2009).

\section{Endnote}




\footnotetext{
${ }^{1}$ It's important to note that although in cinema lesbians seem less likely to be represented within the beach and seaside setting, the context of the road movie and particularly the significance of the desert or wild terrain seems to offer a similar prospect of liminal identification and representation. Evidence of this may be see in the films Desert Hearts (1985), Boys on the Side (1995) and Cloudburst (2011). 2 See Barnard and Rist 1999; Cham 1995; Martin 1997; Johnson 1995; Shaw and Dennison 2007.

${ }^{3}$ The psychiatrist (Dr Cukrowicz), played by Montgomery Clift offers resonance, as in real life Clift was a queer man (see Bosworth 1978).
} 
